\title{
Equivalent noise level response to number of vehicles: a comparison between a high traffic flow and low traffic flow highway in Klang Valley, Malaysia
}

\author{
Herni Halim* and Ramdzani Abdullah \\ Department of Environmental Management, Faculty of Environmental Studies, Universiti Putra Malaysia, Serdang, Malaysia
}

\author{
Edited by: \\ Ahmad Zaharin Aris, Universiti Putra \\ Malaysia, Malaysia \\ Reviewed by: \\ loannis Konstantinos Kalavrouziotis, \\ HELLENIC OPEN UNIVERSITY, \\ Greece \\ Taner Yonar, Uludag University, \\ Turkey \\ ${ }^{*}$ Correspondence: \\ Herni Halim, Department of \\ Environmental Management, \\ Faculty of Environmental Studies, \\ Universiti Putra Malaysia, 43400 \\ Serdang, Selangor Darul Ehsan, \\ Malaysia \\ e-mail: hernihalim@yahoo.com
}

\section{HIGHLIGHTS}

- Highway traffic noise is a serious problem in Malaysia

- Heavy traffic flow highway recorded higher noise level compared to low traffic flow

- Noise level stabilized at certain number of vehicles on the road i.e above 500 vehicles.

Although much research on road traffic noise has found that noise level increase are influenced by driver behavior and source-receiver distance, little attention has been paid to the relationship between noise level and total number of vehicles on the road. In this study, 5 days measurement of noise level during peak hour and off peak hour has been carried out at two types of highways; high traffic flow highway (Sungai Besi Expressway) and low traffic flow highway (Duke Highway). Simultaneously, the number of vehicles passing the measurement point were recorded for every $15 \mathrm{~min}$. Findings indicated that heavy traffic flow highway recorded higher noise level compared to low traffic flow highway. It was due to the higher number of vehicles on the heavy traffic flow highway than low traffic flow highway. Other than that, certain particular number of vehicles, noise level keeps stabilization.

Keywords: road traffic noise, noise assessment, total number of vehicles

\section{INTRODUCTION}

Noise pollution is by now recognized worldwide as a major problem for the quality of life in urban areas (Piccolo et al., 2005). The rapid industrialization, commercialization, and urbanization witnessed by many developing countries in recent years has given rise to the steady increase in the environmental noise climate. The environmental noise climate is influenced drastically by road traffic noise because that type of noise produces a continuous sound which fluctuates from hour to hour in irregular trend with the passage of individual vehicles. Thus, road traffic noise has become a fundamental issue of immediate for both the public and policy-makers.

Road traffic noise from especially highways increases due to many factors including noise generated from a vehicle's engine, exhaust, contact between the tires and road surface and interaction between moving vehicles and air that pass through, road condition and traffic management, vehicle speed, and traffic composition. (Cohen and McVoy, 1982; Banerjee et al., 2008; AlMutairi et al., 2009; Swain et al., 2012). Nulty (1987) reviewed that the impact of traffic noise is because of a trend of enhancing the noise output from noise-emitting machines by suitably adjusting the vehicle's silencer. A study conducted in South Eastern Nigeria by Onuu (2000) and in Kolkata, India revealed that sirens and horns are caused to the high environmental noise climate in these cities. A recent study carried out by Nataraja et al. (2010) stated that the distance between source and receiver of the noise influence the noise level in studying areas. However, although much research has found that noise level increase are influenced by driver behavior and source-receiver distance, little attention has been paid to the relationship between noise level and total number of vehicles on the road.

Thus, this study was conducted to reveal the relationship between number of vehicles on the road and noise level at two different types of highways which the first one used by more than 500 vehicles for every 15 min representing heavy traffic flow highway while the second one used by less than 500 vehicles for the same measurement period representing low traffic flow highway. Measurement was carried out during peak hour (0700 to 0900) and off peak hour (2300 to 0100). Due to the lack of studies concerning the effects of a number of vehicles on noise levels in Malaysia, this study aimed to evaluate and analyse the relationship between number of vehicles and noise level considering Malaysia scenario and traffic pattern.

\section{MATERIALS AND METHODS}

The present investigation on evaluation and analysis of the relationship between number of vehicles and noise level conducted in urban residential areas in the city of Klang Valley, Malaysia. Two sampling locations of highways in the Klang Valley city selected for noise pollution study were Sungai Besi Expressway and Duke Highway. Noise levels in "A" weighting network were measured using the Integrating Sound Level Meter which complies with the International Electrotechnical Commissioning (IEC) 61672 Class 1 Standard. The brief information of equipment used was briefly describe in Table 1. 
The meter was held $1.5 \mathrm{~m}$ above the ground surface on the highway shoulder at a distance of $1 \mathrm{~m}$ from the pavement edge following the ISO 1996-2: 2007. This method was similar to other noise monitoring programmes in Thailand (Kaiyasith et al., 1992; Pamanikabud, 1997), and Ontario (Hajek, 1975) and was in conformity with the IEC, BSI, and ISO standards after calibration of the microphone. For each sampling location, noise measurement was carried out with three sets of measurement with the period of 5 days with $2 \mathrm{~h}$ of monitoring during peak time (0700 to 0900$)$ as well as off peak time (2300 to 0100$)$ for each set, with data of number of vehicles as well as composition

Table 1 | Brief information of integrating sound level meter used for the study.

Origin

Model

France

Manufacturer

of traffic were recorded for every 15 min during measurement. The noise monitoring activities were carried out from 14 June 2011 until 17 July 2011. The average data of the three sets were then used as the results in this paper. Any vehicle passing the site was entered in the appropriate column on the tally sheet provided. The exact number of vehicles which included the heavy vehicles (lorries with more than two axles and buses), cars, and motor cycles were the counted. All the noise monitoring experiments were carried out under ideal meteorological condition with relative humidity, temperature, and wind speed of sites varied from 76 to $93 \%, 26$ to $29^{\circ} \mathrm{C}$, and 0 to $0.7 \mathrm{~m} / \mathrm{s}$.

\section{RESULTS AND DISCUSSION}

A strong relationship between traffic volume and noise level has been reported in the study carried out by Ma et al. (2006) and Swain et al. (2012). As traffic volume increase noise level also increases. In our study, the correlation between the total number of vehicles for every $15 \mathrm{~min}$ and $\mathrm{L}_{\mathrm{eq}}$ were tested. The analysis

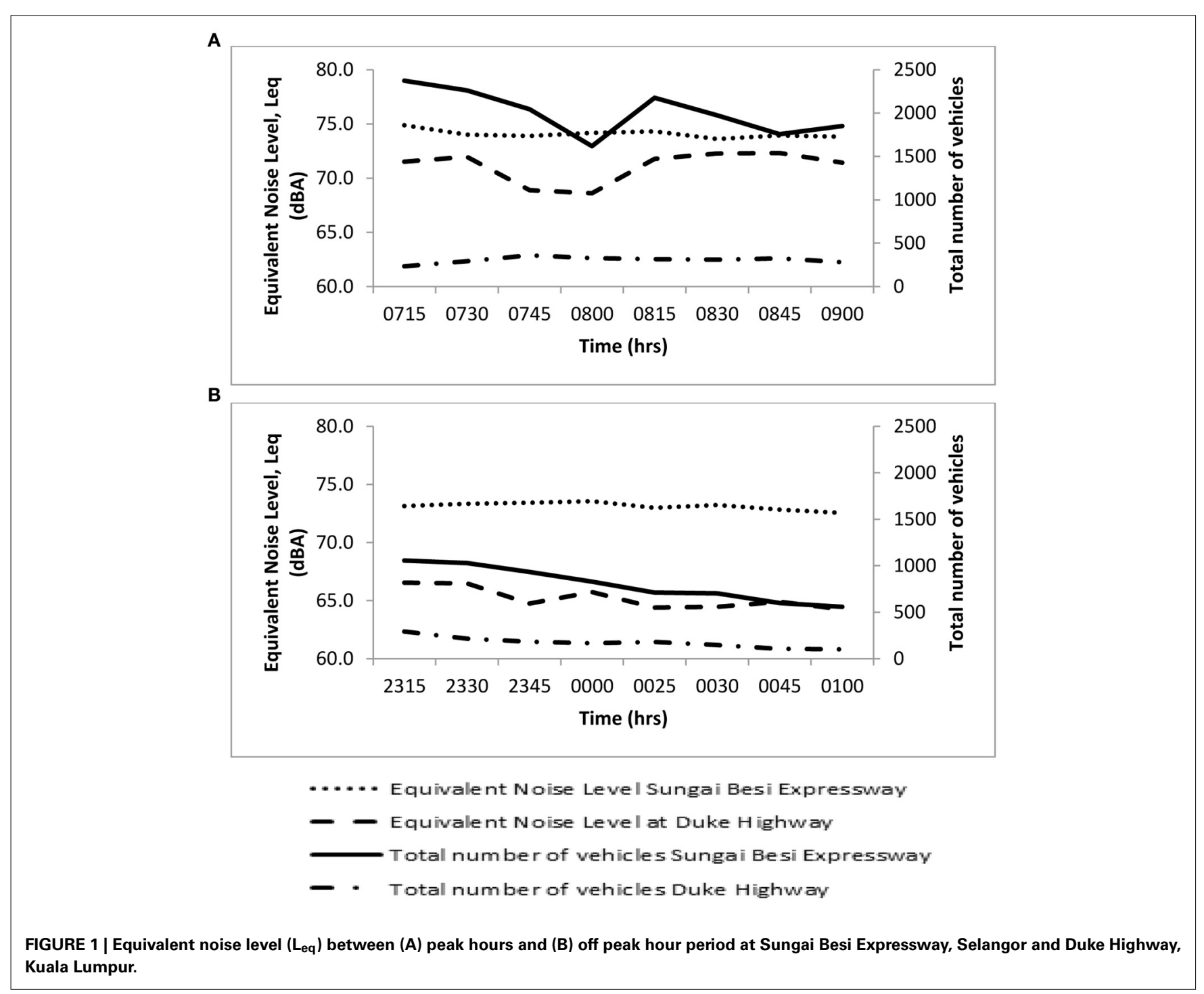


of noise level at two highways were carried out during peak and off peak hours. Figure 1 presents the noise level at Sungai Besi Expressway and Duke Highway from 0700 to 0900 representing peak hours and 2300 to 0100 representing off peak hours.

In Figure 1, the noise level of heavy traffic flow highway which is Sungai Besi Expressway was higher compared to low traffic flow highway, Duke Highway. Other than that, the highest noise level was $74.9 \mathrm{dBA}$ during peak hours and $73.4 \mathrm{dBA}$ during off peak hours while the lowest $\mathrm{L}_{\mathrm{eq}}$ was 73.8 and $72.6 \mathrm{dBA}$, respectively. All the values exceed outdoor noise limit by the World Health Organization (WHO, 2000) as well as Malaysia guidelines (DOE, 2000). Long-term exposure toward noise levels more than $70 \mathrm{~dB}(\mathrm{~A})$ can cause trouble, hypertension, high stress levels, hearing loss, sleep disturbances, and other harmful effects (Field, 1993) to the people living around the highways.

As can be seen from the figure, noise level during peak hours was significantly higher compared to off peak noise level, which is consistent with results obtained in previous studies by Nataraja et al. (2010) However, both graphs show the same fashion of noise level, which the noise level was high at the beginning and gradually decrease toward the end of the measurement. Similarly, the number of vehicles also decline steadily throughout the measurement period. This result may be explained by the fact that the number of vehicles on the road caused the noise level on the highway. This statement is in line with study carried out by Serkan Ozer et al. (2009) in Turkey. However, peak hour does not have that pattern as the noise level drop drastically at 0745 to 0800 but starts increasing afterwards. This situation happens due to the decreasing number of heavy vehicles in that period of time which consequently reduce the noise level (Swain et al., 2012).

Other than that, we can see that Sungai Besi Expressway, with number of vehicles more than 500 during both measurement period of $15 \mathrm{~min}$ has difference of the noise level almost $1 \mathrm{dBA}$ only. However, for Duke Highway where the number of vehicles that pass-by the road less than 500 during measurement of $15 \mathrm{~min}$ has a large difference of noise level by $4 \mathrm{dBA}$ during peak hours and $2.3 \mathrm{dBA}$ during off peak hours. This situation indicates that when the total number of vehicles gives rise to some particular value, noise level keeps stabilization. The same finding also found by $\mathrm{Ma}$ et al. (2006) were in their study, when traffic volume goes beyond 1000 vehicles/h, the change trend of noise level keeps stabilization.

Several changes should be made to solve highway noise problem in Klang Valley, Malaysia. Future mitigation includes erecting roadside noise barriers at sites near residential areas, increases subway used so that less vehicles will be on the highways, and lastly, creates exclusive routes away from residential areas for heavy vehicles.

\section{CONCLUSION}

The results showed that heavy traffic flow highway recorded higher noise level compared to low traffic flow highway. It was due to the higher number of vehicles on the heavy traffic flow highway than low traffic flow highway. This study also revealed that highway noise in Malaysia has reached serious levels compared to WHO (2000) standard where the guidelines stated that noise level should not exceed $55 \mathrm{dBA}$ during daytime and $45 \mathrm{dBA}$ during nighttime. Nearby residential areas would be seriously affected by the transport noise from both highways. Furthermore, the most striking finding in the study was at some particular number of vehicles, noise level keep stabilization. This study also indicated that noise has become one of the major environmental problems of Malaysia and need urgent overcome through more effective enforcement. However, this study needs further investigation will be necessary with much longer period of time to support the conclusion made.

\section{ACKNOWLEDGMENTS}

The author would like to thank Department of Environmental Management, Faculty of Environmental Studies, University of Putra Malaysia for the support of this project. Thanks also to Universiti Sains Malaysia for the Fellowship Scheme and Universiti Putra Malaysia for providing financial support under Research University Grant(RUGS) No. 9365200 to carry out this study.

\section{REFERENCES}

Al-Mutairi, N., Al-Rukaibi, F., and Koushki, P. (2009). Measurements and model calibration of urban traffic noise pollution. Am. J. Environ. Sci. 5, 613-617. doi: 10.3844/ajessp.2009.613.617

Banerjee, D., Chakraborty, S., Bhattacharrya, S., and Gangopadhyay, A. (2008). Evaluation and analysis of road traffic noise in asansol: an industrial town of eastern India. Int. J. Environ. Res. Public Health 5, 165-171. doi: 10.3390/ijerph2008050023

Cohen, L. F., and McVoy, G. (1982). Environmental Analysis of Transportation Systems. New York, NY: Wiley.

DOE. (2000). Malaysia Environmental Quality Report Putrajaya. (Kuala Lumpur: Ministry of Science, Environment and Technology).

Field, J. M. (1993). Effect of personal and situational variables upon noise annoyance in residential areas. J. Acoust. Soc. Am. 93, 2753-2763. doi: $10.1121 / 1.405851$

Hajek, J. J. (1975). "Ontario ministry of transportation and communications. Ontario highway noise prediction method," in Research Report 197 (Downsview, ON).

Kaiyasith, C., Sangbusracomchot, W., and Kanjananavee, A. (1992). Study and Analysis of Traffic Noise on Viphavadee-Rungsit Highway. Thonburi: Department of Civil Engineering, King Mongkut Institute of Technology.

Ma, G., Tian, Y., Ju, T., and Ren, Z. (2006). Assessment of traffic noise pollution from 1989 to 2003 in Lanzhou city. Environ. Monit. Assess. 123, 413-430. doi: 10.1007/s10661-006-1494-6

Nataraja, B., Wei, Y. X., and Abdullah, R. (2010). Effect of traffic noise on sleep: a case study in serdang raya, selangor, malaysia. EnvironmentAsia 3, 149-155.

Nulty, G. J. M. (1987). Impact of transportation noise in some new industrial countries. Appl. Acoust. 21, 81-87. doi: 10.1016/0003-682X(87) 90002-8

Onuu, M. U. (2000). Road traffic noise in Nigeria: measurements, analysis and evaluation of nuisance. J. Sound Vibration 233, 391-405. doi: 10.1006/jsvi. 1999.2832

Pamanikabud, P. (1997). Super-highway traffic noise simulating model with consideration of local traffic vehicle. J. East. Asia Soc. Trans. Stud. 2, 2031-2038.

Piccolo, A., Plutino. D., and Cannistraro, G. (2005). Evaluaion and analysis of the environmental noise of messina, Italy. Appl. Acoust. 66, 447-465. doi: 10.1016/j.apacoust.2004.07.005 
Serkan Ozer, H. Y., Murat, Y., and Pervin, Y. (2009). Evaluation of noise pollution caused by vehicles in the city of tolkat, Turkey. Sci. Res. Essay 14, $1205-1212$.

Swain, B. K., Goswami, S., and Panda, S. K. (2012). Road traffic noise assessment and modeling in Bhubaneswar, India: a comparative and comprehensive monitoring study. Int. J. Earth Sci. Eng. 5, $1358-1370$.

WHO. (2000). "Guidelines for community noise," in A Paper Presented to 6th Congress on Environmental Health (Oslo).

Conflict of Interest Statement: The authors declare that the research was conducted in the absence of any commercial or financial relationships that could be construed as a potential conflict of interest.
Received: 17 January 2014; accepted: 28 April 2014; published online: 24 June 2014. Citation: Halim $H$ and Abdullah $R$ (2014) Equivalent noise level response to number of vehicles: a comparison between a high traffic flow and low traffic flow highway in Klang Valley, Malaysia. Front. Environ. Sci. 2:13. doi: 10.3389/fenvs.2014.00013

This article was submitted to Green and Environmental Chemistry, a section of the journal Frontiers in Environmental Science.

Copyright (c) 2014 Halim and Abdullah. This is an open-access article distributed under the terms of the Creative Commons Attribution License (CC BY). The use, distribution or reproduction in other forums is permitted, provided the original author(s) or licensor are credited and that the original publication in this journal is cited, in accordance with accepted academic practice. No use, distribution or reproduction is permitted which does not comply with these terms. 